\title{
Inflammatory cytokine profile of VEGF and IL-6 from the endometrium of women with and without endometriosis
}

\author{
Ashish Ashish ${ }^{1}$, Kusum Kusum², Sangeeta Rai ${ }^{3}$, Kulsoom Zahra ${ }^{4}$, Surendra Pratap Mishra ${ }^{4}$, \\ Gunjan Rai ${ }^{1}$, Radha Chaube ${ }^{2}$, Royana Singh ${ }^{1 *}$
}

\begin{abstract}
${ }^{1}$ MRU Lab, Department of Anatomy, ${ }^{2}$ Department of Zoology, Institute of Science, ${ }^{3}$ Department of Obstetrics and Gynecology, ${ }^{4}$ Department of Biochemistry, Institute of Medical Science, Banaras Hindu University, Varanasi, Uttar Pradesh, India
\end{abstract}

Received: 09 December 2020

Revised: 10 February 2021

Accepted: 11 February 2021

\section{*Correspondence:}

Dr. Royana Singh,

E-mail: royanasingh@bhu.ac.in

Copyright: (C) the author(s), publisher and licensee Medip Academy. This is an open-access article distributed under the terms of the Creative Commons Attribution Non-Commercial License, which permits unrestricted non-commercial use, distribution, and reproduction in any medium, provided the original work is properly cited.

\begin{abstract}
Background: Endometriosis affects an estimated 176 million women worldwide, which constitutes $10 \%$ of the total female population causing debilitating symptoms of pelvic pain and infertility, which limits the quality of reproductive life of affected women. The present study aimed to assess the serum level of VEGF and proinflammatory marker IL-6 in cases and normal healthy control groups.

Methods: VEGF and IL-6 serum levels were measured by competitive sandwich enzyme-linked immunosorbent assay (ELISA) from 34 subjects with surgically confirmed endometriosis, 16 subjects with adenomyosis and 18 similar age matched healthy controls with no clinical evidence of the disease or detectable endometriotic lesions at the time of surgical examination. Patients were characterized in terms of their socio-demographic and clinically diagnosed characteristics, including the validated infertility and chronic disease registries.

Results: The mean serum level of VEGF was significantly $(\mathrm{p}<0.0001)$ higher in case of endometriosis $(3887 \mathrm{ng} / \mathrm{l})$ followed by adenomyosis $(2588 \mathrm{ng} / \mathrm{l})$ group and lower in case of normal healthy control $(665 \mathrm{ng} / \mathrm{l})$ group. The mean serum IL-6 was found to be highly significant $(\mathrm{p}<0.0001)$ in case of endometriosis $(90.49 \mathrm{pg} / \mathrm{ml})$ followed by adenomyosis $(70.37 \mathrm{pg} / \mathrm{ml})$ group and lower in case of normal healthy control $(22.97 \mathrm{pg} / \mathrm{ml})$ group.

Conclusions: VEGF and IL-6 seems to play a crucial role in the implantation and development of endometriotic lesions, and the disease is associated with significant modulations in the serum levels of VEGF. IL- 6 can be a reliable non-invasive diagnostic marker for endometriosis.
\end{abstract}

Keywords: Cytokine, Endometriosis, Infertility, Inflammation, IL-6, VEGF

\section{INTRODUCTION}

Endometriosis is a chronic inflammatory disease condition in women, where tissues resembling endometrium, usually stromal or glandular, are located outside the uterine cavity. ${ }^{1}$ Menorrhagia, dysmenorrhea, dyspareunia, dyschezia, dysuria, pelvic pain and infertility are the prominent symptoms seen in endometriosis suffering women. ${ }^{2}$ In addition, factors like environmental and dietary elements, immune system, viz. cytokines, interleukins, and intrinsic anomalies in endometrium are also associated with the disease. ${ }^{3,4}$ Many previous studies have assessed the risk factors associated with endometriosis. ${ }^{4}$ Age, race, alcohol usage, body mass index, cigarette smoking, and menstrual characteristics such as early age menarche, menstrual length, cycle regularity, dysmenorrhea, and menstrual flow intensity are all associated with the incidences of endometriosis. ${ }^{5}$ Globally, one in ten women during their reproductive years (between puberty and menopause) are having endometriosis, which is about 176 million women population worldwide suffering from the disease. ${ }^{6}$ This 
could be partially explained by the fact that the gold standard for diagnosis of endometriosis requires direct visualization of lesions at surgery followed by histological confirmation of endometrial glands and stroma in biopsies of suspected lesions. ${ }^{7}$ Additionally, other factors that contribute to the diagnostic delay are treatment of pain with oral contraceptives or nonsteroidal anti-inflammatory drugs and the assumption of dysmenorrhea as a normal event. ${ }^{6}$ Treatments are limited to hormonal therapy with many side-effects and complicated surgical removal of disease, which often needs to be repeated. Retrograde menstruation is a widely accepted theory, Dr. John Sampson explains the pathogenesis. ${ }^{8}$ This theory suggests that during menstrual blood and uterine tissue contractions menstrual endometrial tissue flows back menstruating and implants through the fallopian tubes instead of out of the body on various sites, most commonly in the pelvis, into the oviducts and peritoneal cavity. ${ }^{8}$ It was shown that 76 $90 \%$ of all women experience this endometrial debris, including both epithelial and stromal cells. ${ }^{9}$ However, only in endometriosis patients is this menstrual tissue able to adhere to peritoneal structures, develops a blood supply and grows into an endometriotic lesion. ${ }^{10}$ Therefore, it is likely that the women who are developing endometriosis have genetic, biochemical or immune system dysfunction that does not allow the removal of the debris but rather facilitates menstrual tissue adhesion to peritoneal structures and endometriotic lesion formation. ${ }^{11}$ Indeed, it is well established that women with endometriosis exhibit immune dysfunction in the form of heightened local and systemic inflammation. ${ }^{12,13}$ More specifically, in the plasma and peritoneal fluid (PF), endometriosis patients display aberrant numbers of immune cells and concentrations of cytokines and chemokines that promote a chronic inflammatory environment compared to healthy women. ${ }^{2,14,15}$ The chronic inflammatory environment has also been shown to contribute to the chronic pain and infertility experienced by endometriosis patients. ${ }^{16,17}$

Altered function of immune cells are involved in the developmental cause or consequence of endometriosis, especially an immune dysfunction in relation to macrophages and cells within the peritoneum secreting a number of products of monocytes/macrophages, mainly growth factors and cytokines. ${ }^{18}$ At this level, immune cells are activated by an immune-inflammatory reaction, taken together endometriotic implants and produces high amounts of growth factors, cytokines, and other angiogenic products. ${ }^{19}$

The pivotal angiogenic factor involved in endometriosis pathophysiology and especially in its initiation appears to be the vascular endothelial growth factor (VEGF). ${ }^{20}$ There is a controversy in the current literature regarding VEGF serum and peritoneal fluid (PF) levels in endometriosis patients. Some authors have indicated an increased level of VEGF in serum and in PF, while several others have reported no change in VEGF serum and in PF levels in endometriosis patients. ${ }^{21}$ Neovascularization is essential for a successful implantation of endometrial cells in ectopic sites. VEGF is a part of a heparin-binding protein family, and because the induction of endometrial cell proliferation seems to function by VEGF, it is considered as an essential factor in uterine angiogenesis. $^{22}$

However, endometriosis have also been indicated by systemic immune alterations, which secrets high level of cytokines with the activation of peripheral blood monocytes. A number of cytokines have been studied in the pathogenesis of endometriosis, including interleukin 6 (IL-6), vascular endothelial growth factor (VEGF), and tumour necrosis factor $\alpha(\mathrm{TNF}-\alpha){ }^{23}$ Interleukin-6 is considered to play a potential role in the growth and/or maintenance of ectopic endometrial tissue. Interleukin-6 modulates the secretion of other cytokines and acts as a regulator of inflammation and immunity. ${ }^{24,25}$ It helps in activation of T-cell and B-cell differentiation, and also supress growth of several cell lines. The role of IL-6 has been widely studied in the pathogenesis of endometriosis, but the levels of IL- 6 has been detected both in the peritoneal fluid and in endometriosis patients. ${ }^{26}$ Tumor necrosis factor $-\alpha$ is secreted from activated macrophages, and it has a potent cytotoxic, inflammatory and angiogenic effects. It stimulates the expression of matrix metalloproteinases (MMPs) by endometriotic tissues, and MMPs actively participate in matrix modelling and invasion of endometriotic lesions. ${ }^{26}$ Moreover, etanercept, an anti-TNF therapy, was found to effectively reduce the development of endometriosis. Several authors showed, when these factors in the peritoneal fluid was produced, it was associated with the increase in the level of similar factors in the peripheral blood of patients with endometriosis. $^{17}$

The present study aimed to investigate the serum proinflammatory cytokine profile in patients with endometriosis compared with healthy controls, and to evaluate the sensitivity and specificity of any single cytokine or a combination of cytokines in the prediction of the inflammatory status in endometriosis.

\section{METHODS}

\section{Classification systems of endometriosis}

Numerous proposed systems to classify various forms of endometriosis exist mainly in the American Society of Reproductive Medicine (rASRM) (15), which is modified and renamed into Revised American Society for Reproductive Medicine classification of endometriosis. ${ }^{27,28}$ All of these classifications divide endometriosis into four stages related to the increasing severity of the ovaries lesions, particularly the number of endometrial implants, their depth, and adhesions; stage I: 1-5 points indicates minimal disease i.e., few superficial implants, stage II: 6-15 points score indicates mild disease which includes more and deeper implants, stage III: 16-40 points for moderate disease having many deep implants, small cysts on one or both ovaries and stage IV: 
$>40$ points indicate severe condition with many deep implants, large cysts on one or both ovaries with dense adhesions. ${ }^{29-31}$

\section{Ethical clearance}

Ethical clearance was obtained from the institutional ethical committee of our institution before starting the study (No. Dean/2018/EC/936). Written informed consent from all the patients and healthy individuals are obtained.

\section{Study subjects}

The present case-control study was conducted between September 2017-2020 (3 years) at the Department of Obstetrics and Gynaecology, Sir Sunderlal Hospital, Institute of Medical Sciences, Banaras Hindu University, Varanasi $\left(25^{\circ} 20^{\prime} \mathrm{N}, 83^{\circ} 0^{\prime} \mathrm{E}\right)$. The data was selected from 18 fertile women as control, 34 infertile women with endometriosis and 16 women with adenomyosis. Data were randomly collected and the details of the lifestyle, habits, and familial history of patients were recorded. Patients with endometriosis were evaluated according to the revised American Society for Reproductive Medicine (rASRM) classification system. ${ }^{26}$ All the subjects were of Indian ethnicity from eastern Uttar Pradesh and Bihar, the two states of northern India. All the subjects were informed about the study and their consents were taken prior to the start of the study.

\section{Inclusion criteria}

Patients between 18 to 50 year age group, having their reproductive organs were included in the study. All the patients of primary or secondary infertility who were subjected to diagnostic hysterolaparoscopy have endometriosis and BMI less than $32 \mathrm{~kg} / \mathrm{m}^{2}$ were also included.

\section{Exclusion criteria}

Patients with other causes of chronic pelvic pain, including infectious diseases, pelvic inflammatory disease (PID), adhesions due to previous surgeries or infections, were excluded from this study.

\section{Clinical characteristic of subject included}

Characteristic points included were the age, residence, physical and socioeconomic status of the subjects, type and duration of infertility, menstrual cycle-age of onset, frequency and its flow, an association of symptoms like dysmenorrhoea, dyspareunia, chronic pelvic pain, urinary symptoms and their correlation to the stage of endometriosis. Physical examination of the study subject was done. Findings were analysed concerning BMI, adnexal masses, mobility of uterus, and the presence of tenderness. TVS and MRI have been suggested for the detection of deep-infiltrating lesions. MRI and computed tomography, including ultrasound were evaluated for diagnosis. Diagnostic laparoscopy, a gold standard tool for direct visualization of the pelvis, helps in identifying the etiology of the patients' pain, was advised and evaluated. The laparoscopic staging was done based on the revised AFS scoring system, which categorizes the findings into four stages. ${ }^{32}$

\section{Blood collection and serum preparation}

Approximately $5 \mathrm{ml}$ of blood was obtained through venepuncture under aseptic condition in a clean, plain, red topped dry vial. Blood was kept for 10 minutes before centrifugation. Serum was separated from the blood through centrifugation at 3000 RPM for 10 minutes and stored in aneliquote at $-20^{\circ} \mathrm{C}$ until required for analysis. Less than 5 hour was allowed between blood collection and processing. Serum aliquots were then frozen at $-80^{\circ} \mathrm{C}$ until measurement of VEGF and IL-6 serum levels.

\section{Laboratory analysis}

VEGF: ELISA kit (Cat. No. E0080Hu) uses the Sandwich-ELISA principle. The plate has been precoated with Human VEGF antibody. VEGF present in the sample was added and it binds to antibodies coated on the wells. And then biotinylated human VEGF antibody was added and it binds to VEGF in the sample. Then streptavidin-HRP was added and it bindsto the biotinylated VEGF antibody. After incubation unbound streptavidin-HRP was washed away during a washing step. Substrate solution was then added and color was developed in proportion to the amount of human VEGF. The reaction was terminated by addition of acidic stop solution and absorbance was measured at $450 \mathrm{~nm}$. The standard curve range was $20-6000 \mathrm{ng} / \mathrm{l}$. The sensitivity of the kit was $10.42 \mathrm{ng} / \mathrm{L}$. The intra-assay precision and inter-assay precision were $\mathrm{CV}<8 \%, \quad \mathrm{CV}<10 \%$ respectively.

IL-6: ELISA kit (Cat. No. E-EL-H0102) uses the Sandwich-ELISA principle. The micro ELISA plate has been pre-coated with an antibody specific to Human IL-6. Standards or samples were added to the micro ELISA plate wells and combined with the specific antibody present in the well. Then a biotinylated detection antibody specific for human IL-6 and avidin-horseradish peroxidase (HRP) conjugate were added successively to each micro plate well and incubated for one hour. Free components of the wells were washed away after three times of washing. Now, in each well the substrate solution was added. Only those wells appear in blue colour that contain human IL-6, biotinylated detection antibody and avidin-HRP conjugate. By adding stop solution the enzyme-substrate reaction was terminated and the colour turned yellow. The absorbance was measured through ELISA reader at a wavelength of 450 $\mathrm{nm}$. The OD value of the sample or standard is proportional to the concentration of human IL-6. The 
specificity of this kit was $4.69 \mathrm{pg} / \mathrm{ml}$ and the detection range was $7.81-500 \mathrm{pg} / \mathrm{ml}$.

\section{Statistical analysis}

Statistical analysis was performed using the SPSS IBM Statistics software version 23.0. Distributions of data sets obtained in the study were checked for normality using Kolmogorov-Smirnoff test. Means were separated using Tukey's test when data were normally distributed and variances were homogeneous (Bartlett's test for equal variances). The data were presented as Mean \pm SD. Oneway ANOVA test was performed for the statistical significance of the difference, in mean values of variables among several groups. Two-tailed p-values less than 0.05 were considered statistically significant and p-values less than 0.0001 were considered to be highly significant. All the results were expressed in Mean \pm SD.

\section{RESULTS}

Age may be a factor for the occurrence of endometriosis, but the present study has shown that most of the women of reproductive age (32 \pm 8.08$)$ suffering from endometriosis had a mean BMI value of $21.75 \pm 2.32$ (Table 1). Women living in urban areas are diagnosed earlier for the disease, while those living in rural areas suffer from the disease much severely but are diagnosed in their later stages, probably due to lack of health knowledge.

Table 1: Demographic characteristics related to stages of the disease, including age, residence and BMI.

\begin{tabular}{|c|c|c|c|c|c|c|}
\hline \multirow{2}{*}{ Variable $(n=221)$} & & Stage $1(n=19)$ & Stage $2(n=80)$ & Stage $3(n=75)$ & Stage $4(n=47)$ & \multirow[b]{2}{*}{$P$ value } \\
\hline & & $\mathbf{N}(\%)$ & $\mathbf{N}(\%)$ & $\mathbf{N}(\%)$ & $\mathbf{N}(\%)$ & \\
\hline \multirow{2}{*}{ Age (years) } & $<32$ & $9(47.4)$ & $37(46.3)$ & $35(46.7)$ & $19(40.4)$ & \multirow{2}{*}{0.903} \\
\hline & $>32$ & $10(52.6)$ & $43(53.8)$ & $40(53.3)$ & $28(59.6)$ & \\
\hline Mean \pm SD & $32.10 \pm 8.08$ & & & & & \\
\hline \multirow{2}{*}{ Residence } & Urban & $7(36.8)$ & $21(26.3)$ & $28(37.3)$ & $16(34.0)$ & \multirow{2}{*}{0.487} \\
\hline & Rural & $12(63.2)$ & $59(73.8)$ & $47(62.7)$ & $31(66.0)$ & \\
\hline \multirow[t]{2}{*}{ BMI $\left(\mathbf{k g} / \mathbf{m}^{2}\right)$} & $<22$ & $6(31.6)$ & $43(53.8)$ & $32(42.7)$ & $25(53.2)$ & \multirow{3}{*}{0.215} \\
\hline & $>22$ & $13(68.4)$ & $37(46.3)$ & $43(57.3)$ & $22(46.8)$ & \\
\hline Mean \pm SD & $21.75 \pm 2.32$ & & & & & \\
\hline
\end{tabular}

Table 2: Concentration of VEGF (ng/L) and IL-6 (pg/ml) in three groups; endometriosis, adenomyosis and normal healthy control.

\begin{tabular}{|c|c|c|c|c|c|}
\hline Parameters & Groups & Cases (Mean \pm SD) & $\begin{array}{l}\text { Control }(\mathrm{n}=18) \\
(\text { Mean } \pm \text { SD })\end{array}$ & $P$ value & $\begin{array}{l}\text { Intergroup comparison } \\
\text { one way ANOVA }\end{array}$ \\
\hline \multirow{2}{*}{$\begin{array}{l}\text { Concentration of } \\
\text { VEGF (ng/l) }\end{array}$} & Endo $(n=34)$ & $3887 \pm 1886 a$ & \multirow{2}{*}{$665 \pm 479$} & $<0.0001$ & \multirow{2}{*}{$\mathrm{F}=28.98 \mathrm{a}$} \\
\hline & Adeno $(n=16)$ & $2588 \pm 879 b$ & & $<0.0001$ & \\
\hline \multirow{2}{*}{$\begin{array}{l}\text { Concentration of } \\
\text { IL-6 }(\mathrm{pg} / \mathrm{ml})\end{array}$} & Endo $(n=34)$ & $90.49 \pm 45.91 \mathrm{a}$ & \multirow{2}{*}{$22.97 \pm 14.16$} & $<0.0001$ & \multirow{2}{*}{$\mathrm{F}=18.93 \mathrm{~b}$} \\
\hline & Adeno $(n=16)$ & $70.37 \pm 37.88 b$ & & $<0.0001$ & \\
\hline
\end{tabular}

Here, $\mathrm{a}=\mathrm{p}<0.0001 ; \mathrm{b}=\mathrm{p}<0.0001$. One way ANOVA test was used for intergroup comparison.

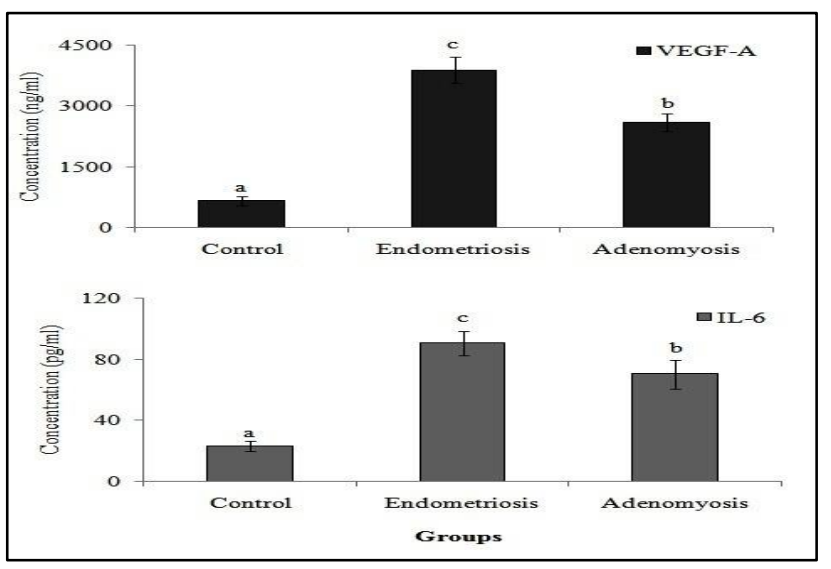

Figure 1: Concentration of VEGF and IL-6 in three groups; healthy control, endometriosis and adenomyosis.
Table 2 shows significant differences in mean serum VEGF level between fifty patients of endometriosis, adenomyosis and eighteen normal healthy control group. The concentration of VEGF was expressed in $\mathrm{ng} / \mathrm{ml}$. Statistically significant differences in the level of VEGF between the control and case groups $(p<0.0001)$ was observed. The concentration of IL- 6 was expressed in $\mathrm{ng} / \mathrm{l}$, and it was also significantly high $(\mathrm{p}<0.0001)$ in case with endometriosis followed by adenomyosis shown in Figure 1.

\section{DISCUSSION}

Recent studies have shown an increased IL-6 production by endometriotic cells in both basal and cytokinestimulated conditions compared with normal condition. Interleukin-6 is a cytokine derived from T-cells, secreted by macrophages, lymphocytes, fibroblasts, and 
endothelial cells. ${ }^{33}$ Its secretion is increased by peritoneal macrophages in cases of endometriosis. Generally IL-6 inhibits the growth of endometrial cells, the effect of which is lost in endometriotic tissues. IL-6 has been investigated regarding the pathogenesis of endometriosis, and also as a predictor of disease. ${ }^{34}$ Elevated serum IL-6 are considered to be biological marker for differential diagnosis of endometriosis. Previous studies revealed conflicting result about elevated serum IL-6 levels in endometriosis. However many of them are in favour of significant rise in serum IL-6 level in case of endometriosis. Serum IL-6 provides best discrimination between subjects with endometriosis and normal healthy controls and the diagnostic value of this marker increased with the findings. It's because the serum IL-6 did not change significantly during any phase of menstrual cycle in either groups. ${ }^{35}$

Vascular endothelial growth factor (VEGF) is a 30-46 $\mathrm{kDa}$, heparin-binding growth factor that is active as a disulphide-linked homo-dimer, and its a potent mitogen, morphogen, and chemo-attractant for endothelial cells. ${ }^{36}$ We have demonstrated that the level of VEGF in serum, are elevated in women with endometriosis when compared with normal healthy control group. The principal source of the VEGF are macrophages and that anti-VEGF antibody abolished the enhanced endothelial cell proliferation induced by conditioned medium from macrophages isolated from the peritoneal cavity of women with endometriosis. ${ }^{37}$ These findings demonstrate that these activate macrophages are the main source of VEGF in endometriosis and its expression is directly regulated by estradiol and progesterone. Since endometriosis is characterized by pronounced vascularization in and around the ectopic tissue, elevated levels of the potent angiogenic growth factor VEGF especially in the peritoneal fluid and the presence of VEGF-positive macrophages in the ectopic tissue are of clinical importance for this disease to occur. ${ }^{38}$ Therefore, Vascular endothelial growth factor-induced angiogenesis may be a critical aspect of the pathophysiology of endometriosis.

The limitation of this study is that, it does not include other factors which are directly or indirectly related to activation pathway of VEGF and IL-6.

\section{CONCLUSION}

Endometriosis is an enigmatic gynecological disease, where it's known that endometrial glands and tissues invade to a new place and neovascularization (new blood vessel formation) occurs. But it was a point from beginning, to study factors involved in inflammation or neovascularization for endometrial tissues implantation. This is now well know that VEGF, is a signalling protein, promoting the new blood vessel formation, whereas IL-6, is a potential cytokine involved in inflammation of tissues. Thus this study will be useful to put these as being a marker of inflammation and adhesion of endometric implants. It will further be useful for a successful target for early disease diagnosis and control.

\section{ACKNOWLEDGMENTS}

This research was sponsored by Multi-Disciplinary Research Units (MRUs), a grant by ICMR-Department of Health Research.

Funding: No funding sources Conflict of interest: None declared

Ethical approval: The study was approved by the Institutional Ethics Committee (No. Dean/2018/EC/936)

\section{REFERENCES}

1. Klemmt PA, Starzinski-Powitz A. Molecular and cellular pathogenesis of endometriosis. Curr Womens Health Rev. 2017;13(999):1-11.

2. Kusum, Rai S, Chaube R. Endometriosis: role of aromatase and recent advances in the disease treatment. Austin J Obs Gynecol. 2019;6(2).

3. Riazi H, Tehranian N, Ziaei S, Mohammadi E, Hajizadeh E, Montazeri A. Clinical diagnosis of pelvic endometriosis: A scoping review. BMC Womens Health. 2015;15(1):01.

4. Saceanu SM, Patrascu S, Patrascu A, Surlin V. Endometriosis: when and how we treat. Fertil Orient Female Reprod Surg. 2017:61.

5. Giudice LC, Kao LC. Endometriosis. Lancet. 2004;364(9447):1789-99.

6. Adaji E, Ahankari A, Myles P. An investigation to identify potential risk factors associated with common chronic diseases among the older population in India. Indian $\mathrm{J}$ Community Med. 2017;42(1):46-52.

7. Hsu AL, Khachikyan I, Stratton P. Invasive and noninvasive methods for the diagnosis of endometriosis. Clin Obstet Gynecol. 2010;53(2):413-9.

8. Ashish A, Kusum K, Rai S, Singh R. Endometriosis a brief review: evaluation of crucial risk factors and current treatment regimes. Int $\mathrm{J} \mathrm{Adv}$ Med. 2020;7(12):1896.

9. Carpinello OJ, Sundheimer LW, Alford CE, Taylor $\mathrm{RN}$, De Cherney AH, Feingold KR, et al. Endometriosis- Endotext; 2000.

10. Acién P, Velasco I. Endometriosis: a disease that remains enigmatic. ISRN Obstet Gynecol. 2013;2013:1-12.

11. Audebert A. Endometriosis. In: Encyclopedia of Endocrine Diseases. MDText.com, Inc.; 2018: 498-505.

12. Miller JE, Monsanto SP, Ahn SH, Khalaj K, Fazleabas AT, Young SL, et al. Interleukin-33 modulates inflammation in endometriosis. Scient Rep. 2017;7(1):1-1.

13. Kyama CM, Debrock S, Mwenda JM, D'Hooghe TM. Potential involvement of the immune system in 
the development of endometriosis. Reprod Biol Endocrinol. 2003;1.

14. Bulun SE. Endometriosis. In: Yen and Jaffe's Reproductive Endocrinology: Physiology, Pathophysiology, and Clinical Management. 8th edn. Elsevier Inc.; 2019:609-42.e7.

15. de Almeida Asencio F, Ribeiro HA, Ayrosa Ribeiro P. Symptomatic endometriosis developing several years after menopause in the absence of increased circulating estrogen concentrations: a systematic review and seven case reports. Gynecol Surg. 2019;16(1):1-11.

16. Shigesi N, Kvaskoff M, Kirtley S. The association between endometriosis and autoimmune diseases: a systematic review and meta-analysis. Hum Reprod Update. 2019;25(4):486-503.

17. Zondervan KT, Becker CM, Koga K, Missmer SA, Taylor RN, Viganò P. Endometriosis. Nat Rev Dis Prim. 2018;4(1):9.

18. Vallvé-Juanico J, Houshdaran S, Giudice LC. The endometrial immune environment of women with endometriosis. Hum Reprod Update. 2019;25(5):565-92.

19. Malutan AM, Drugan T, Costin N, Ciortea R, Bucuri C, Rada MP, Mihu D. Pro-inflammatory cytokines for evaluation of inflammatory status in endometriosis. Cent Eur J Immunol. 2015;40(1):96.

20. Malutan A, Drugan T, Georgescu C, Ciortea R, Bucuri C, Bobric A, et al. Vascular Endothelial Growth Factor serum levels in women with advanced endometriosis. Acta Endocrinol. 2016;12(1):7.

21. Gagné D, Pagé M, Robitaille G, Hugo P, Gosselin D. Levels of vascular endothelial growth factor (VEGF) in serum of patients with endometriosis. Hum Reprod. 2003;18(8):1674-80.

22. Ferrara N. Role of vascular endothelial growth factor in the regulation of angiogenesis. Kidney Int. 1999;56(3):794-814.

23. Lin YH, Chen YH, Chang HY, Au HK, Tzeng CR, Huang YH. Chronic niche inflammation in endometriosis-associated infertility: Current understanding and future therapeutic strategies. Int $\mathrm{J}$ Mol Sci. 2018;19(8).

24. Wu MH, Hsiao KY, Tsai SJ. Endometriosis and possible inflammation markers. Gynecol Minim Invasive Ther. 2015;4(3):61-7.

25. Wu MH, Wang CA, Lin CC, Chen LC, Chang WC, Tsai SJ. Distinct regulation of cyclooxygenase-2 by interleukin-1 $\beta$ in normal and endometriotic stromal cells. J Clin Endocrinol Metab. 2005;90(1):286-95.

26. Li S, Fu X, Wu T, Yang L, Hu C, Wu R. Role of interleukin-6 and its receptor in endometriosis. Med Sci Monit. 2017;23:3801-7.

27. As-Sanie S, Black R, Giudice LC, Valbrun TG, Gupta J, Jones B, et al. Assessing research gaps and unmet needs in endometriosis. Am J Obstet Gynecol. 2019;221(2):86-94.

28. Donnez J. Introduction: From pathogenesis to therapy, deep endometriosis remains a source of controversy. Fertil Steril. 2017;108(6):869-71.

29. Foti PV, Farina R, Palmucci S, Vizzini IA, Libertini $\mathrm{N}$, Coronella $\mathrm{M}$, et al. Endometriosis: clinical features, MR imaging findings and pathologic correlation. Insights Imag. 2018;9(2):149-72.

30. Eisenberg VH, Weil C, Chodick G, Shalev V. Epidemiology of endometriosis: a large populationbased database study from a healthcare provider with 2 million members. BJOG Int J Obstet Gynaecol. 2018;125(1):55-62.

31. Moradi M, Parker M, Sneddon A, Lopez V, Ellwood D. Impact of endometriosis on women's lives: a qualitative study. BMC Womens Health. 2014;14(1):123.

32. Ashish A, Kusum K, Rai S, Singh R. Endometriosis a brief review: evaluation of crucial risk factors and current treatment regimes. Int $\mathrm{J} \mathrm{Adv}$ Med. 2020;7(12):1896.

33. Tsudo T, Harada T, Iwabe T, Tanikawa M, Nagano $\mathrm{Y}$, Ito $\mathrm{M}$, et al. Altered gene expression and secretion of interleukin-6 in stromal cells derived from endometriotic tissues. Fertil Steril. 2000;73(2):205-11.

34. Laganà $\mathrm{AS}$, Garzon $\mathrm{S}$, Götte $\mathrm{M}$, Viganò $\mathrm{P}$, Franchi M, Ghezzi F, et al. The pathogenesis of endometriosis: Molecular and cell biology insights. Int J Mol Sci. 2019;20(22).

35. Martinez S, Garrido N, Coperias JL, Pardo F, Desco J, Garcia-Velasco JA, et al. Serum interleukin-6 levels are elevated in women with minimal-mild endometriosis. Hum Reprod. 2007;22(3):836-42.

36. Shibuya M. Vascular endothelial growth factor (VEGF) and its receptor (VEGFR) signaling in angiogenesis: a crucial target for anti- and proangiogenic therapies. Genes Cancer. 2011;2(12):1097-105.

37. McLaren J, Prentice A, Charnock-Jones DS, Millican SA, Müller KH, Sharkey AM, et al. Vascular endothelial growth factor is produced by peritoneal fluid macrophages in endometriosis and is regulated by ovarian steroids. J Clin Invest. 1996;98(2):482-9.

38. McLaren J. Vascular endothelial growth factor and endometriotic angiogenesis. Hum Reprod Update. 2000;6(1):45-55.

Cite this article as: Ashish A, Kusum K, Rai S, Zahra K, Mishra SP, Rai G, et al. Inflammatory cytokine profile of VEGF and IL-6 from the endometrium of women with and without endometriosis. Int J Reprod Contracept Obstet Gynecol 2021;10:965-70. 